\title{
Optimizing the Preparation Parameters of Nanocrystalline Zirconia for Catalytic Applications
}

\section{M.M. Abd El-Latif ${ }^{1 \dagger}$, M.S. Showman ${ }^{1)}$, A.M. Ibrahim ${ }^{2,3)}$ and M.M. Soliman ${ }^{4)}$}

1) Fabrication Technology Department, Advanced Technology and New Materials Research Institute (ATNMRI), City of Scientific Research and Technological Applications (SRTA-City), Alexandria, Egypt

2) Dharyya Colleges for Science and Atrs Qassim University, Al Qassim, Saudi Arabia

3) Surface Chemistry and Catalysis Laboratory, Physical Chemistry Department, National Research Center, Al Buhouth St., Cairo, Egypt

4) Department of Materials Science, Institute of Graduate Studies and Research, Alexandria University, Alexandria, Egypt

[Manuscript received 6 January 2013, in revised form 19 May 2013]

(c) The Chinese Society for Metals and Springer-Verlag Berlin Heidelberg

\begin{abstract}
Nanocrystalline zirconia powder with high surface area and high tetragonal phase percentage is prepared by the precipitation method using ammonium hydroxide as a precipitating agent. The $\mathrm{pH}$ of precipitation, preparation temperature and calcinations' temperature are optimized. Crystallite size, specific surface area, tetragonal phase percentage and the thermal stability of the prepared samples are identified by different characterization tools such as X-ray diffraction (XRD), thermo gravimetric analysis (TGA), differential scanning calorimetry (DSC), BET surface area, scanning electron microscopy (SEM) and transmission electron microscopy (TEM). The optimum preparation parameters for obtaining nanocrystalline zirconia with high percentage of tetragonal phase and high surface area are $\mathrm{pH} 9$, preparation temperature of $80{ }^{\circ} \mathrm{C}$ and calcinations' temperature of $400{ }^{\circ} \mathrm{C}$. The sample prepared under optimized conditions showed a high specific surface area of $179.2 \mathrm{~m} / \mathrm{g}$, high tetragonal phase percentage of $81 \%$ and high catalytic activity $(60 \%)$ for synthesis of butyl acetate ester.
\end{abstract}

KEY WORDS: Tetragonal zirconia; Nanocrystalline zirconia; Precipitation synthesis; Catalytic properties of zirconia; Esterification with zirconia

\section{Introduction}

Pure zirconia exhibits three polymorphs of monoclinic, tetragonal and cubic symmetries. The monoclinic phase is stable at room temperature and transforms to the tetragonal phase at $1443 \mathrm{~K}$ during heating, while this phase transforms to the cubic one at $2643 \mathrm{~K}^{[1,2]}$. Several different oxides are added to zirconia in order to stabilize the tetragonal and/or cubic phases such as magnesium oxide, yttrium oxide, calcium oxide, and cerium oxide.

Pure $\mathrm{ZrO}_{2}$ nanopowders were synthesized by different methods, for examples, a gel-combustion

† Corresponding author. Prof., Ph.D.; Tel.: +3 4593414;

Fax: +3 4593414; E-mail address: amona1911@yahoo.com (M.M. Abd El-Latif)

DOI: $10.1007 / \mathrm{s} 40195-013-0008-0$ $\operatorname{method}^{[3]}$, sol gel method ${ }^{[4,5]}$, precipitation through urea decomposition ${ }^{[6]}$ and slow precipitation with ammonia from aqueous solution of zirconyl chloride octahydrate $^{[7]}$. By precipitation method, the grain size, particle shape, agglomerate size, and specific surface area can be modified within certain degree by controlling the precipitation and calcinations' conditions.

The formation mechanism of hydrous zirconia from zirconyl precursors is strongly related to its aquatic chemistry. When $\mathrm{ZrOCl}_{2} \cdot 8 \mathrm{H}_{2} \mathrm{O}$ is dissolved in water, cyclic tetramer complexes $\left[\mathrm{Zr}(\mathrm{OH})_{2} \cdot 4 \mathrm{H}_{2} \mathrm{O}\right]_{4}^{8+}$ are formed as dominant entities ${ }^{[8]}$. Gradual addition of ammonia to the solution results in species dramatic changes in $\mathrm{pH}$ causing the hydrolysis of zirconium cations. In such conditions, the tetramers release protons from the terminal water to form $\left[\mathrm{Zr}(\mathrm{OH})_{2+n} \cdot(4-\right.$ $\left.n) \mathrm{H}_{2} \mathrm{O}\right]_{4}^{(8-4 n)+}$. Zirconium oxide and compounds con- 


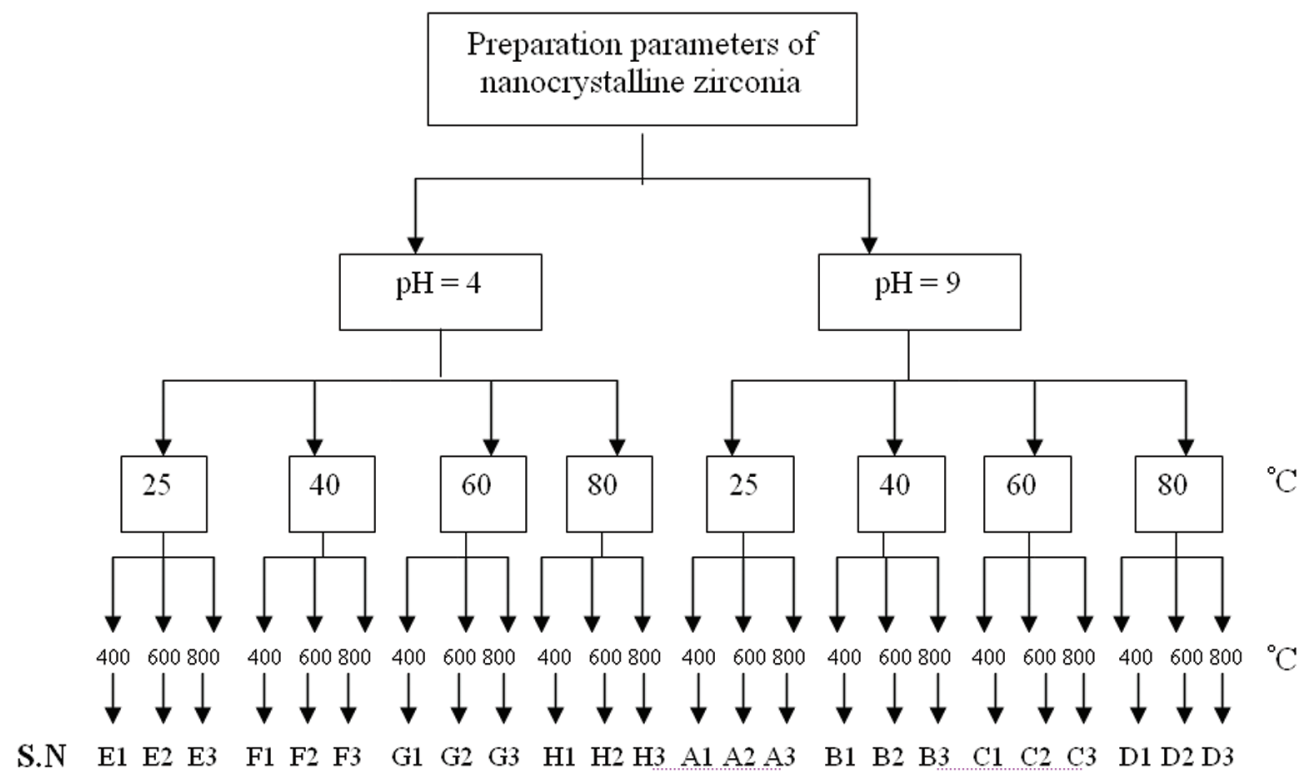

Fig. 1 Various preparation parameters which are studied for the preparation of zirconia

taining zirconium are increasingly being recognized as useful catalytic materials. In particular, zirconium oxide is an important support material for catalysis, having both acidic and basic properties ${ }^{[9]}$. Zirconia has a high melting point of about $2700{ }^{\circ} \mathrm{C}$ and is stable even under reducing conditions. Unlike titania, it does not form reactive electron-hole pairs under photo irradiation ${ }^{[10]}$. The use of zirconia as a catalyst or as a support is effective only when the compound has a high surface area which remains stable under process conditions ${ }^{[11]}$. Zirconia is sometimes classified as a wide band gap semiconductor and tends to become more conductive at higher temperatures ${ }^{[12]}$. The present work is undertaken to establish the effects of synthesis conditions on the crystallite size, crystalline phase and catalytic properties of zirconia. Zirconia is precipitated from zirconyl chloride solutions at both low and high $\mathrm{pH}$ with heat treatment. The structure and thermal behavior of zirconia are characterized with X-ray diffraction (XRD), thermal analysis (TGA, DSC), BET surface area, scanning electron microscope (SEM) and transmission electron microscope (TEM). The prepared samples are applied in esterification reaction between acetic acid and butanol in order to study their catalytic activities to produce butyl acetate ester.

\section{Materials and Methods}

\subsection{Materials}

Zirconylchloride octahydrate $\mathrm{ZrOCl}_{2} \cdot 8 \mathrm{H}_{2} \mathrm{O}(98 \%)$ is obtained from across, ammonia solution $\mathrm{NH}_{4} \mathrm{OH}$ $(30 \%)$ is obtained from MP biomedical products, acetic acid $\mathrm{CH}_{3} \mathrm{COOH}$ (99.8\%) is obtained from bro- labo products, N-Butanol (n-butyl alcohol) is obtained from Adwic products.

\subsection{Zirconia Powder Preparation}

Nanocrystalline zirconia is prepared by precipitation method under both acidic and alkaline conditions. Different samples of zirconia are prepared by adding (30\%) ammonia solution to a solution of $0.05 \mathrm{~mol} / \mathrm{L} \mathrm{ZrOCl}_{2} \cdot 8 \mathrm{H}_{2} \mathrm{O}$ in a deionized water under heating until reaching to preparation temperature $\left(25,40,60,80^{\circ} \mathrm{C}\right)$ at certain $\mathrm{pH}(4,9)$. All these solutions are continuously stirred for $1 \mathrm{~h}$ and then aged for $24 \mathrm{~h}$ until forming precipitates, which is washed several times with distilled water until the negative test for $\mathrm{Cl}^{-}$, the precipitates are dried at $100{ }^{\circ} \mathrm{C}$ for 4 $\mathrm{h}$ to obtain the samples. The samples are calcined in air for $4 \mathrm{~h}$ at three different calcinations' temperatures $\left(400,600\right.$ and $\left.800{ }^{\circ} \mathrm{C}\right)$ as illustrated in Fig. 1.

\subsection{Sample characterization}

\subsubsection{X-ray diffraction analysis (XRD)}

Crystal phases and crystallite size of the prepared samples are obtained by X-Ray diffractometer (XRD7000Schimadzu, U.S.A), operating with $\mathrm{Cu} K_{\alpha}$ radiation $(\lambda=0.154060 \mathrm{~nm})$ generated at $30 \mathrm{kV}$ and $30 \mathrm{~mA}$. Scans are performed at $2^{\circ} / \mathrm{min}$ for $2 \theta$ values between $10^{\circ}$ and $90^{\circ}$. The crystallite size $(D)$ in $\mathrm{nm}$ is calculated from the reflection of tetragonal zirconia phase at (111) peak and of monoclinic phase at (-111) peak using the Schererr relationship ${ }^{[13]}$ :

$$
D=\frac{k \lambda}{\beta \cos \theta}
$$

where $k$ is the crystallite shape constant $(\sim 0.9), \lambda$ 
is the radiation wavelength $\left(10^{-1} \mathrm{~nm}\right), \beta$ is the line width (radians) and $\theta$ is the Bragg angle. The composition (f) of each phase was calculated from the Gaussian areas ${ }^{[11]}$ :

$$
\begin{aligned}
\mathrm{f}_{\text {monoclinic }} & =\frac{\sum(h \times w)_{\text {monoclinic }}}{\sum(h \times w)_{\text {monoclinic and tetragonal }}} \\
\mathrm{f}_{\text {tetragonal }} & =\frac{\sum(h \times w)_{\text {tetragonal }}}{\sum(h \times w)_{\text {monoclinic and tetragonal }}}
\end{aligned}
$$

where $h$ is the height of the characteristic peaks and $w$ is the half width obtained from X-ray diffraction pattern.

\subsubsection{Morphological characterization}

The prepared samples are examined using scanning electron microscope (JEOL, Model JSM 6360LA, Japan) to investigate the homogeneity of the samples and to determine particles size. Prior to the investigation, the samples are coated with gold using a sputter coating machine (model: S150B, Edwards High Vacuum Ltd., England) in order to avoid the build-up of local electrical charges.

Particle size and morphology of the powders are investigated using transmission electron microscopy (JEOL, model 200CX, Japan). Samples are prepared by sonicating $1 \mathrm{mg}$ of as-synthesized sample in $10 \mathrm{~mL}$ ethanol. A few drops of the resulting suspension are then put onto a grid coated with carbon.

\subsubsection{Surface area (BET)}

The surface area and the porosity of the samples are determined by the conventional BET (Beckman coulter, SA 3100, USA) method at liquid nitrogen temperature. Before each measurement, the samples were degassed at $200{ }^{\circ} \mathrm{C}$ for at least $30 \mathrm{~min}$ or until no more water is seen to be desorbed.

\subsubsection{Thermal analysis}

Thermal stability and the weight losses from the uncalcined samples during the reaction process are calculated using thermo gravimetric analyzer (TGA50-Schimadzu, Japan) and the differential scanning calormetry (DSC-50-Schimadzu, Japan). The measurements are carried out with a heating rate of $10{ }^{\circ} \mathrm{C} / \mathrm{min}$ up to $1000{ }^{\circ} \mathrm{C}$ under flow of $\mathrm{N}_{2}$.

\subsection{Catalytic activity measurement}

The catalyst activity in the esterification reaction between acetic acid and butanol is investigated in a stirred batch reflux system at a temperature of $75^{\circ} \mathrm{C}$. A three-necked flask equipped with a condenser and stirrer of $700 \mathrm{r} / \mathrm{min}$ is charged with $50 \mathrm{~mL}$ of acetic acid, $25 \mathrm{~mL}$ of $\mathrm{n}$-butanol and $0.1 \mathrm{~g}$ of the prepared zirconia catalyst. Then, the system is heated up to the reaction temperature. The reaction temperature is maintained by means of a thermostatic water bath in which the reactor was immersed for $4 \mathrm{~h}$. The resultant sample is analyzed by a gas chromatograph GC (Chrompack CP9001) equipped with a flame ionization detector and a thermal conductivity detec- tor. GC analysis confirmed that no by-products are formed.

\section{Results and Discussion}

\subsection{Crystalline structure}

From the XRD patterns shown in Fig. 2 and Fig. 3, it is clear that the samples contain both tetragonal and monoclinic phases and their percentages change with the calcination's and preparation temperatures. At calcinations' temperature of $400{ }^{\circ} \mathrm{C}$, the main phase is tetragonal. As the calcinations' temperature increases, the tetragonal phase percentage decreases. At $800{ }^{\circ} \mathrm{C}$, a complete transformation occurs, and only monoclinic phase is observed. This behavior is common for all samples except for the samples prepared in basic medium and at preparation temperature of $80^{\circ} \mathrm{C}$. The XRD patterns of these samples show that at all calcination's temperatures; the tetragonal phase is the main phase. This may be attributed to the fact that the tetragonal phase is stable at high preparation temperature ${ }^{[14]}$. The precipitation of hydrous zirconia under acidic conditions is more difficult than that under alkaline conditions. This is due to the potential difficulty during washing the precipitate formed at low $\mathrm{pH}$ values in order to remove anions ${ }^{[15-17]}$. From Table 1, at low calcinations' temperature $\left(400{ }^{\circ} \mathrm{C}\right)$, for samples prepared at room temperature, the tetragonal phase percentage decreases with increasing the $\mathrm{pH}$ from 4 to 9 . While for samples prepared at higher temperatures $\left(40,60,80^{\circ} \mathrm{C}\right)$, the tetragonal phase percentage increases with the increasing the $\mathrm{pH}$ from 4 to 9 , this is in a good agreement with the work done by Chuah $^{[18]}$. From the data listed in Table 2, increasing the calcinations' temperature will cause an increasing in the crystallite size, this is due to that, during calcinations', surface hydroxyls condensation causes the nucleation of new oxide crystals and the growth of the existing ones ${ }^{[11]}$. Crystallite size of both monoclinic and tetragonal phase decreases as the preparation temperature increases from $25^{\circ} \mathrm{C}$ to $80^{\circ} \mathrm{C}$. This may be attributed to the dimerization of $\mathrm{Zr}(\mathrm{OH})_{4}$ by eliminating water from the double hydroxo groups to form oxo bridges at high preparation temperature ${ }^{[19]}$. The increase in the preparation temperature causes changes in the structure of the hydrous zirconia precursor and leads to a more dehydrated oxo-hydroxide. The dehydrated oxo-hydroxide formed at high temperature decomposes yielding to very fine crystallites of zirconia. This results in small crystallite size and high surface area of the prepared samples ${ }^{[20]}$. The samples prepared in acidic medium ( $\mathrm{pH} 4$ ) show the same behavior as in basic medium ( $\mathrm{pH} 9$ ) but the crystallite size of tetragonal phase slightly decreases with the increase of the calcination temperatures. This may be due to the preparation method which results in different phase compositions and crystalline size distributions ${ }^{[4]}$. 

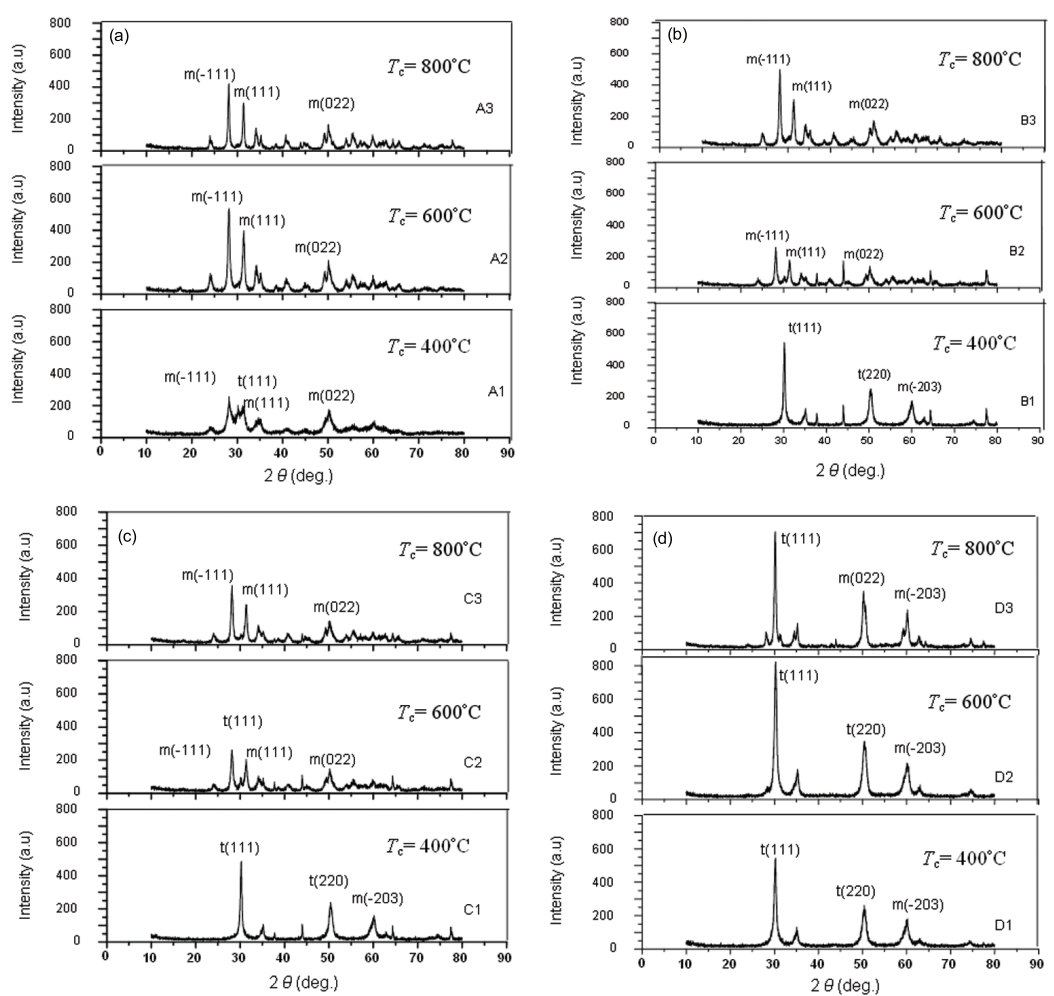

Fig. 2 XRD diffraction patterns of prepared zirconia from $0.05 \mathrm{~mol} / \mathrm{L}$ solution of zirconyl chloride in basic medium at different calcination temperatures $\left(400,600\right.$ and $800{ }^{\circ} \mathrm{C}$ ) and preparation temperatures of $25^{\circ} \mathrm{C}$ (a), $40{ }^{\circ} \mathrm{C}(\mathrm{b}), 60{ }^{\circ} \mathrm{C}(\mathrm{c})$ and $80{ }^{\circ} \mathrm{C}(\mathrm{d})$
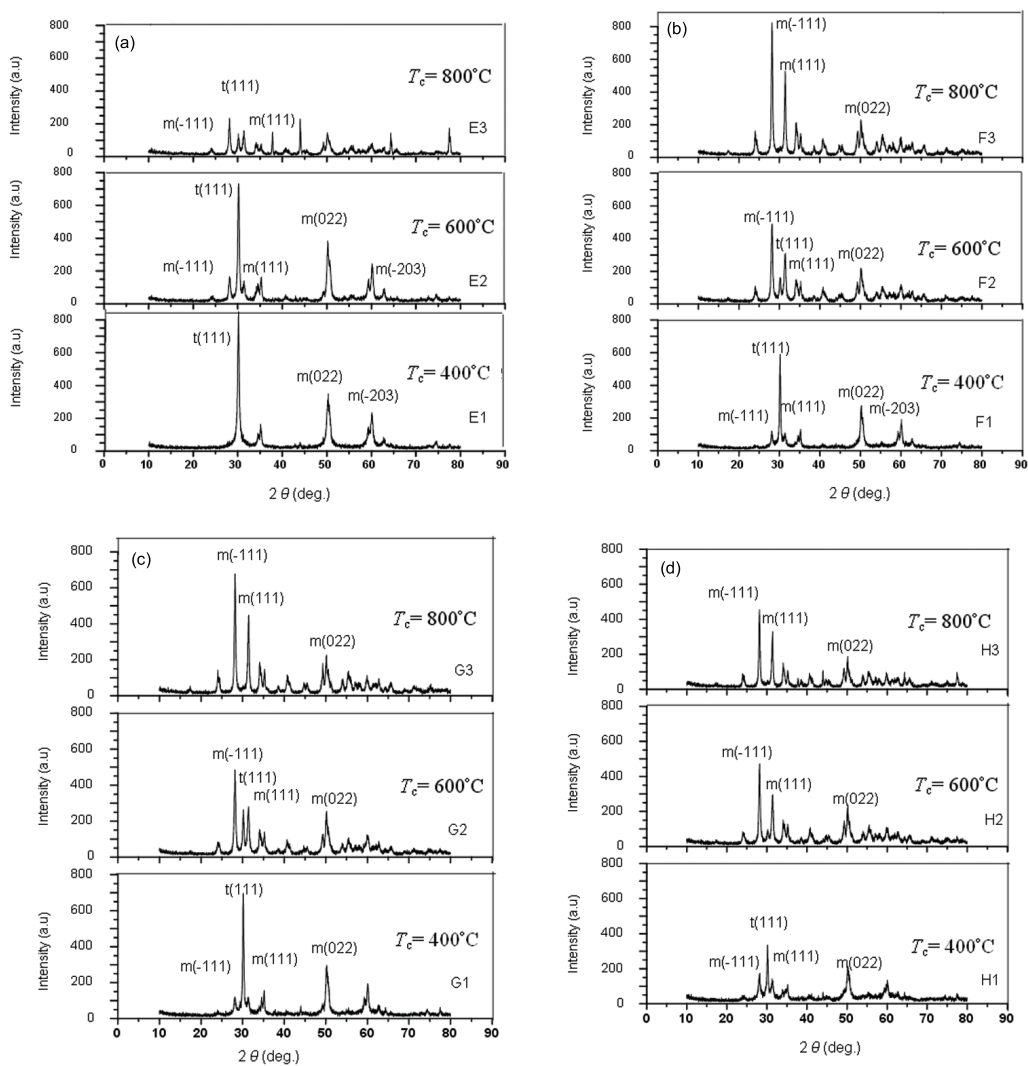

Fig. 3 XRD diffraction patterns of prepared zirconia from $0.05 \mathrm{~mol} / \mathrm{L}$ solution of zirconyl chloride in acidic medium at different calcination temperatures $\left(400,600\right.$ and $800{ }^{\circ} \mathrm{C}$ ) and preparation temperatures of $25{ }^{\circ} \mathrm{C}(\mathrm{a}), 40{ }^{\circ} \mathrm{C}(\mathrm{b}), 60{ }^{\circ} \mathrm{C}(\mathrm{c})$ and $80{ }^{\circ} \mathrm{C}(\mathrm{d})$ 
M.M. Abd El-Latif et al.: Acta Metall. Sin. (Engl. Lett.), 2013, 26(5), 565-573.

Table 1 Phase composition of zirconia samples prepared in acidic and basic medium

\begin{tabular}{cccccc}
\hline \multirow{2}{*}{$\begin{array}{c}\text { Calcination } \\
\text { temperature }\left({ }^{\circ} \mathrm{C}\right)\end{array}$} & $\begin{array}{c}\text { Preparation } \\
\text { temperature }\left({ }^{\circ} \mathrm{C}\right)\end{array}$ & \multicolumn{4}{c}{ Phase composition (\%) } \\
\cline { 3 - 5 } & & 57 & 43 & 39.55 & 60.45 \\
& 25 & 54.6 & 45.4 & 77.6 & 22.4 \\
& 40 & 43.7 & 56.3 & 78.8 & 21.2 \\
& 60 & 42.2 & 57.8 & 81 & 19 \\
& 80 & 43.1 & 56.9 & 0 & 100 \\
600 & 16.7 & 83.3 & 7.6 & 92.4 \\
& 25 & 9.7 & 90.3 & 9.8 & 90.2 \\
& 40 & 5 & 95 & 78.8 & 21.2 \\
& 60 & 14.6 & 85.4 & 0 & 100 \\
800 & 80 & 8.4 & 9.6 & 0 & 100 \\
& 25 & 0 & 100 & 0 & 100 \\
& 40 & 0 & 100 & 51.5 & 48.5 \\
\hline
\end{tabular}

Table 2 Crystallite size of zirconia samples prepared in acidic and basic medium

\begin{tabular}{|c|c|c|c|c|c|}
\hline \multirow{2}{*}{$\begin{array}{c}\text { Calcination } \\
\text { temperature }\left({ }^{\circ} \mathrm{C}\right)\end{array}$} & \multirow{2}{*}{$\begin{array}{c}\text { Preparation } \\
\text { temperature }\left({ }^{\circ} \mathrm{C}\right)\end{array}$} & \multicolumn{4}{|c|}{ Crystallite size (nm) } \\
\hline & & Tetragonal & Monoclinic & Tetragonal & Monoclinic \\
\hline \multirow[t]{4}{*}{400} & 25 & 27.87 & 27.37 & 20.7 & 2.5 \\
\hline & 40 & 25.9 & 25.2 & 18.2 & 12.43 \\
\hline & 60 & 25.5 & 21 & 13.94 & 12 \\
\hline & 80 & 20.1 & 15.3 & 4.48 & 7.23 \\
\hline \multirow[t]{4}{*}{600} & 25 & 20.4 & $30-$ & 16.85 & \\
\hline & 40 & 20.3 & 27.1 & 21.59 & 16.176 \\
\hline & 60 & 21.54 & 21.54 & 18.72 & 14.67 \\
\hline & 80 & 19.8 & 20.6 & 13.94 & 8.63 \\
\hline \multirow[t]{4}{*}{800} & 25 & 21.6 & 40.7 & - & 22.3 \\
\hline & 40 & 21.2 & 29 & - & 17.21 \\
\hline & 60 & - & 23.1 & - & 16.9 \\
\hline & 80 & - & 23.1 & 19.1 & 16.34 \\
\hline
\end{tabular}

\subsection{Thermal behavior}

Fig. 4 and Fig. 5 show the TG-DTG and DSC thermal profiles of the samples prepared at temperature of $80{ }^{\circ} \mathrm{C}$ in basic $(\mathrm{pH} 9)$ and acidic $(\mathrm{pH} 4)$ medium respectively. The samples prepared in basic medium show a total weight loss of $19.903 \%$. The weight loses up to $200{ }^{\circ} \mathrm{C}$ are approximately equivalent to the removal of both adsorbed and coordinated waters and the weight loss observed between $200{ }^{\circ} \mathrm{C}$ and $300{ }^{\circ} \mathrm{C}$ corresponds to the decomposition of $\mathrm{Zr}\left(\mathrm{OH}_{4}\right)$ into amorphous $\mathrm{ZrO}_{2}{ }^{[4,21]}$. The DSC profile shows an endothermic peak around $90{ }^{\circ} \mathrm{C}$, indicating the adsorbed water loss. A sharp exothermic peak observed around $440{ }^{\circ} \mathrm{C}$ is related to the fast crystallization of amorphous phase into tetragonal zirconia which in turn recrystallizes into the monoclinic phase at higher temperatures ${ }^{[22]}$. For sample prepared in acidic medium, the weight loss at room temperature up to $120{ }^{\circ} \mathrm{C}$ is corresponding to the removal of adsorbed water. The weight loss observed at temperatures from $120^{\circ} \mathrm{C}$ to $235^{\circ} \mathrm{C}$ indicates the removal of some water molecules present in the hydrous zirconia. After dehydration, the samples are progressively decomposed into amorphous zirconia due to dehydrox- ylation with increasing temperature. There is an additional peak at about $430{ }^{\circ} \mathrm{C}$ which is attributed to the transition from an amorphous to the monoclinic phase of zirconia ${ }^{[22]}$.

\subsection{Surface area}

As preparation temperature increases from $25^{\circ} \mathrm{C}$ to $80^{\circ} \mathrm{C}$ for samples prepared in both basic $(\mathrm{pH} 9)$ and acidic ( $\mathrm{pH} 4)$ mediums, the specific surface areas of calcined samples are also increased as shown in Fig. 6 and Fig. 7. Increasing the calcinations' temperatures from $400{ }^{\circ} \mathrm{C}$ to $800{ }^{\circ} \mathrm{C}$ for samples prepared in basic medium ( $\mathrm{pH}$ 9) will reduce the surface areas of prepared samples as shown in Fig. 6. Increasing the calcinations' temperature from $400{ }^{\circ} \mathrm{C}$ to $600{ }^{\circ} \mathrm{C}$ for samples prepared in acidic medium ( $\mathrm{pH} 4)$ and at preparation temperatures of $25{ }^{\circ} \mathrm{C}, 40{ }^{\circ} \mathrm{C}$ will enhance the specific surface area, while samples calcined at $800{ }^{\circ} \mathrm{C}$ have a reduced specific surface area as shown in Fig. 7. The specific surface area of zirconia prepared in acidic medium and at higher preparation temperatures (60, $80^{\circ} \mathrm{C}$ ) decreases with the increase of the calcinations' temperatures from $400{ }^{\circ} \mathrm{C}$ to $800{ }^{\circ} \mathrm{C}$. These results agree with those obtained by Chuah et al. ${ }^{[11]}$. At pH 9 , the maximum specific surface area $\left(179.23 \mathrm{~m}^{2} / \mathrm{g}\right)$ 


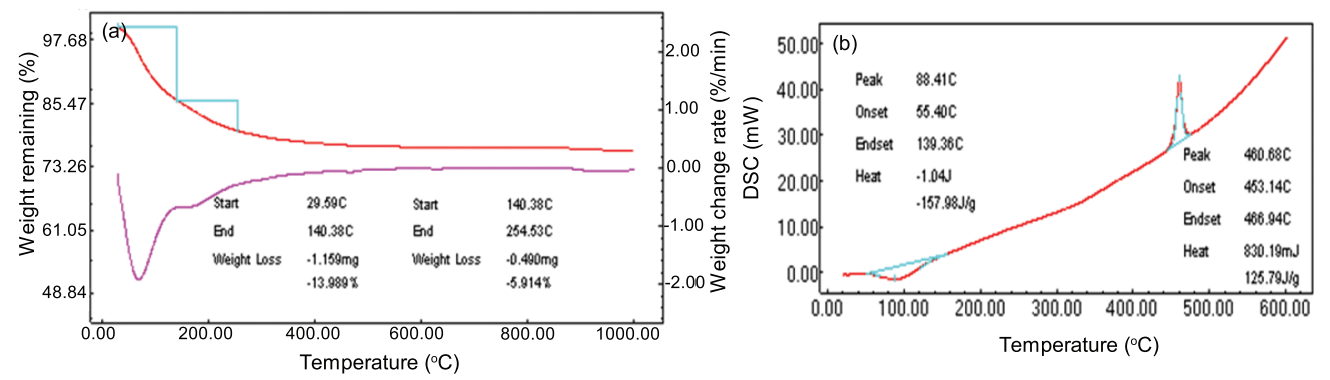

Fig. 4 Thermal profiles of the sample prepared in basic medium at temperature of $80^{\circ} \mathrm{C}$ : (a) TG-DTG; (b) DSC
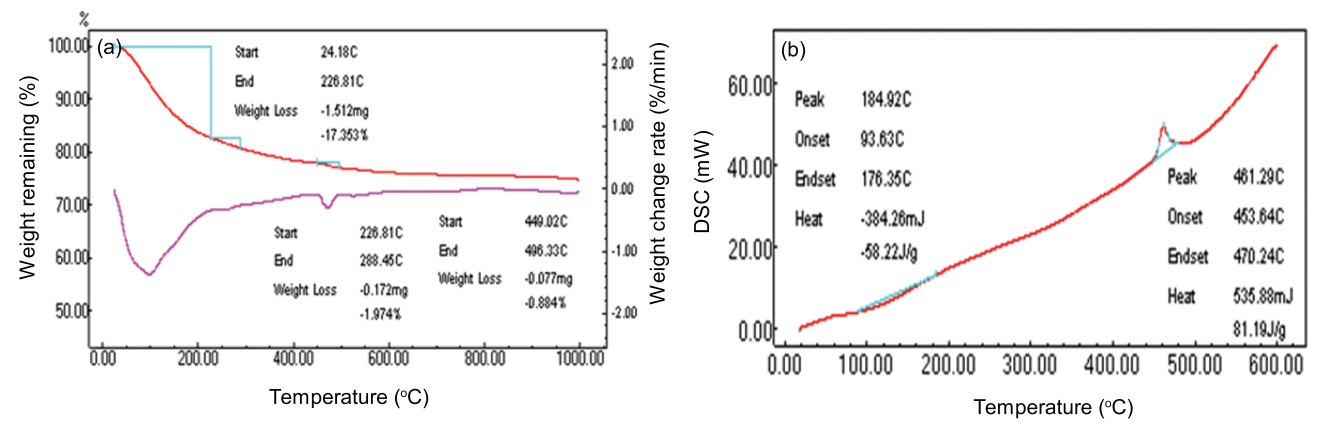

Fig. 5 Thermal profiles of the sample prepared in acidic medium at temperature of $80{ }^{\circ} \mathrm{C}$ : (a) TG-DTG; (b) DSC

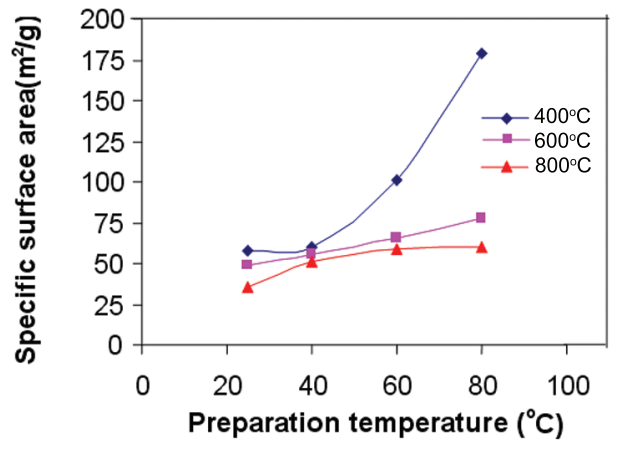

Fig. 6 Effect of preparation temperatures on the specific surface area for samples prepared in basic medium and calcined at different temperatures of 400,600 and $800{ }^{\circ} \mathrm{C}$

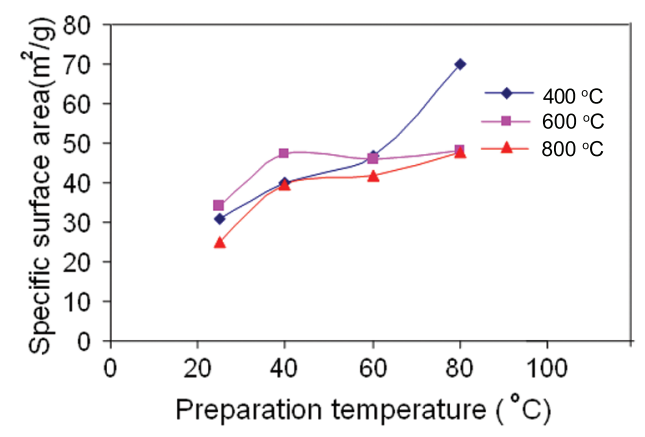

Fig. 7 Effect of preparation temperatures on the specific surface area for samples prepared in acidic medium and calcined at different temperatures of 400,600 and $800{ }^{\circ} \mathrm{C}$ is obtained for sample prepared at temperature of $80^{\circ} \mathrm{C}$ and calcined at temperature of $400{ }^{\circ} \mathrm{C}$. While at $\mathrm{pH} 4$, the maximum specific surface area $\left(69.8 \mathrm{~m}^{2} / \mathrm{g}\right)$ is obtained for sample prepared at room temperature and calcined at $800{ }^{\circ} \mathrm{C}$. The specific surface areas of samples prepared at $\mathrm{pH} 4$ is much lower than those of samples prepared at $\mathrm{pH}$ 9. This may be related to the increase of solubility of the hydrous zirconia, as found by Adair et al. ${ }^{[23]}$.

\subsection{Morphology}

Fig. 8 and Fig. 9 show SEM micrographs of the samples prepared in basic and acidic mediums respectively at $80{ }^{\circ} \mathrm{C}$ and calcined at 400 and $600{ }^{\circ} \mathrm{C}$. A non-uniform distribution of agglomerated particles is shown for the prepared samples. These particles are formed by aggregation of their primary particles and the differences in their morphology can be attributed to the different preparation conditions ${ }^{[24]}$. For acidic and basic samples, the particles calcined at temperature of $400{ }^{\circ} \mathrm{C}$ are nearly uniform. These samples aggregate tightly (hard agglomeration) and cannot be dispersed in the subsequent processing. While the particles calcined at $600{ }^{\circ} \mathrm{C}$, are loose (soft agglomeration) and can be dispersed in the subsequent processing. TEM micrograph of the prepared samples at $80{ }^{\circ} \mathrm{C}$ and calcined at 400 and $600{ }^{\circ} \mathrm{C}$ are shown in Fig. 10 and Fig. 11. Microscopic examinations of the prepared samples show spherical particles consisting of aggregated nanocrystallites. The microstructure 


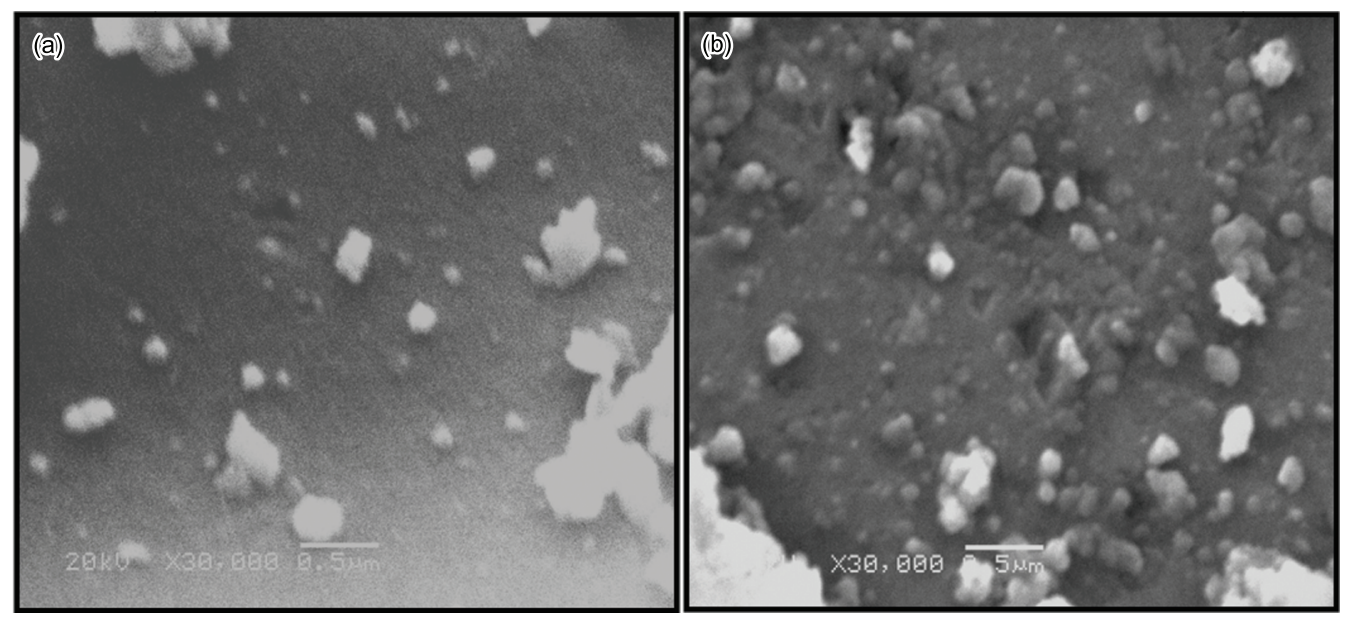

Fig. 8 SEM images of nanocrystalline zirconia samples prepared in basic medium at $80{ }^{\circ} \mathrm{C}$ with calcination temperatures of $400{ }^{\circ} \mathrm{C}$ (a) and $600{ }^{\circ} \mathrm{C}(\mathrm{b})$

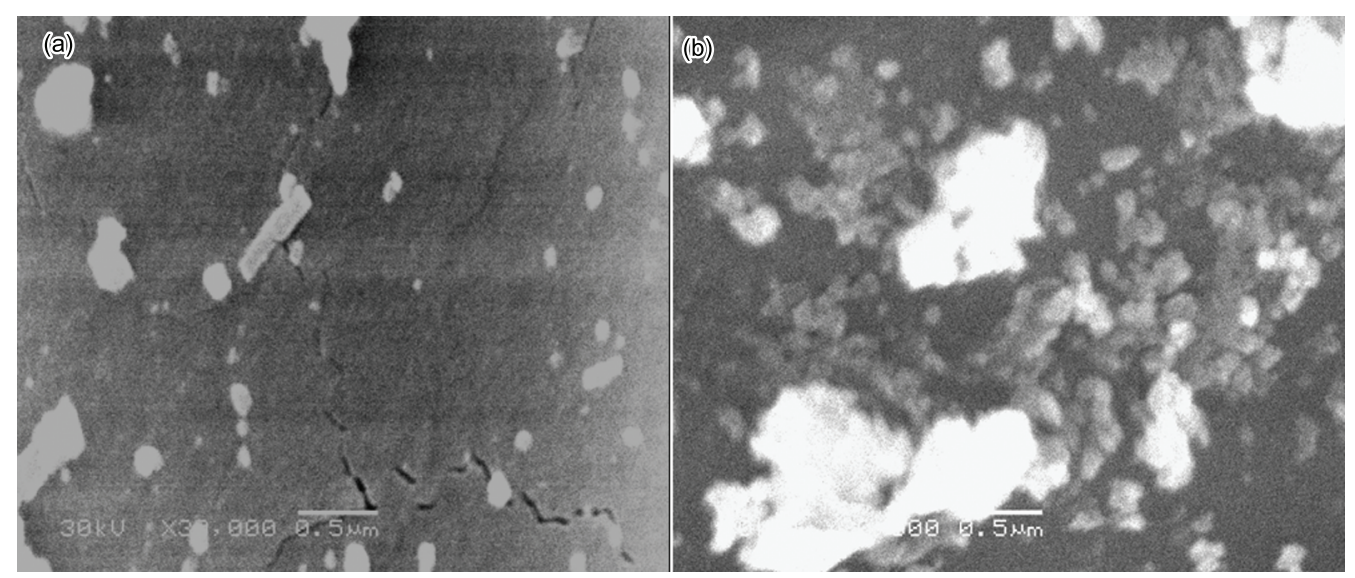

Fig. $9 \mathrm{SEM}$ images of nanocrystalline zirconia samples prepared in acidic medium at $80{ }^{\circ} \mathrm{C}$ with calcination temperatures of $400{ }^{\circ} \mathrm{C}$ (a) and $600{ }^{\circ} \mathrm{C}(\mathrm{b})$
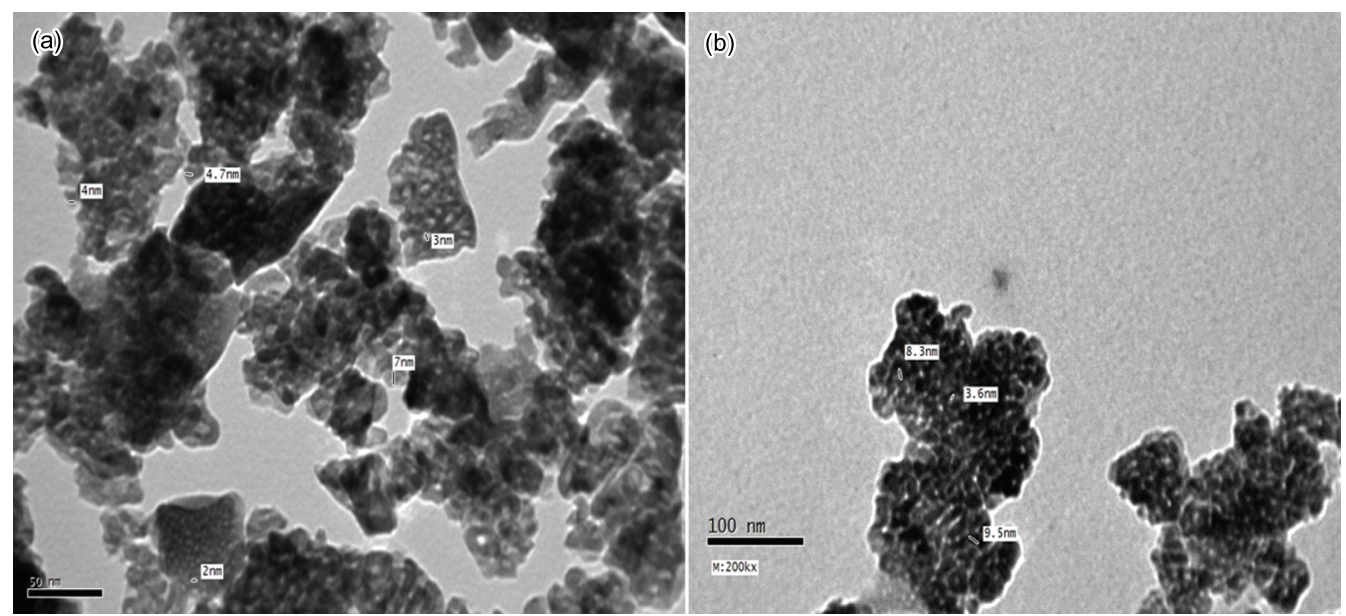

Fig. 10 TEM images of nanocrystalline zirconia samples prepared in basic medium at $80{ }^{\circ} \mathrm{C}$ with calcination temperatures of $400{ }^{\circ} \mathrm{C}$ (a) and $600{ }^{\circ} \mathrm{C}(\mathrm{b})$

of the samples exhibited fine particle morphologies. Most of the particles have a slightly irregular form with crystallite size ranged from 4 to $26 \mathrm{~nm}$. The range is consistent with the crystallite sizes calculated from Scherrer equation ${ }^{[25]}$. These figures indicate that the particles form an interconnected network meso- 


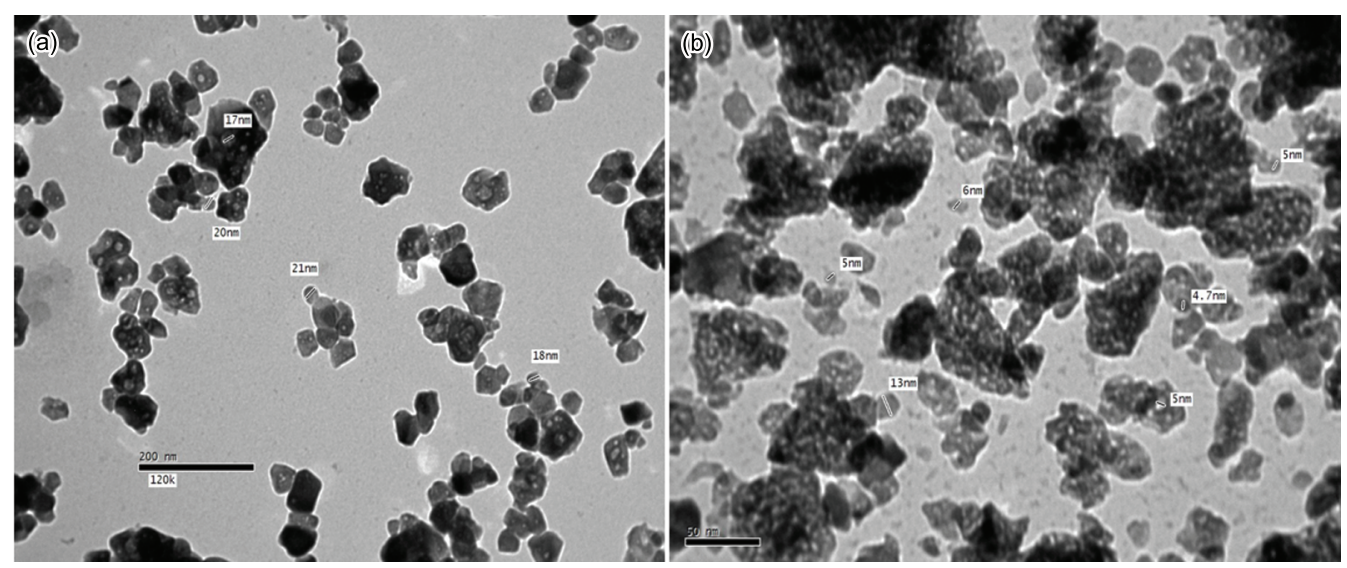

Fig. 11 TEM images of nanocrystalline zirconia samples prepared in acidic medium at $80{ }^{\circ} \mathrm{C}$ with calcination temperatures of $400{ }^{\circ} \mathrm{C}$ (a) and $600{ }^{\circ} \mathrm{C}(\mathrm{b})$

Table 3 The yield of butyl acetate by zirconia catalyst prepared in basic medium

\begin{tabular}{cccc}
\hline Used catalyst & Surface area $\left(\mathrm{m}^{2} / \mathrm{g}\right)$ & Tetragonal percentage $(\%)$ & Butyl acetate yield (\%) \\
\hline A1 & 57.46 & 39.55 & 28.65 \\
B1 & 59.749 & 77.6 & 36.46 \\
C1 & 100.79 & 78.8 & 38 \\
D1 & 179.236 & 81 & 60.3 \\
A2 & 48.337 & 0 & 26 \\
B2 & 55.7 & 7.6 & 32 \\
C2 & 65.88 & 9.8 & 37.5 \\
D2 & 77.551 & 78.8 & 40.6 \\
\hline
\end{tabular}

Table 4 The yield of butyl acetate by zirconia catalyst prepared in acidic medium

\begin{tabular}{cccc}
\hline Used catalyst & Surface area $\left(\mathrm{m}^{2} / \mathrm{g}\right)$ & Tetragonal percentage $(\%)$ & Butyl acetate yield $(\%)$ \\
\hline E1 & 30.751 & 57 & 28 \\
F1 & 40.186 & 54.6 & 28.8 \\
G1 & 46.641 & 43.7 & 35.75 \\
H1 & 69.79 & 42.2 & 37.4 \\
E2 & 34.249 & 43.1 & 19.36 \\
F2 & 47.11 & 16.7 & 23.8 \\
G2 & 45.84 & 9.7 & 33.4 \\
H2 & 48.24 & 5 & 37 \\
\hline
\end{tabular}

porous structure which is very useful for catalytic applications $^{[26]}$. The micrographs show large aggregates of fine zirconia particles due to the large surface energy ${ }^{[27]}$. By increasing the calcination temperatures, the size of zirconia nanoparticles within the aggregates increases. This may be due to the rapid coalescence of the primary particles and their sintering ${ }^{[28]}$. These results are in good agreement with the data obtained from XRD patterns shown in Fig. 2 and Fig. 3.

\subsection{Catalytic activity of prepared nanocrystalline zir- conia}

The activities of the prepared zirconia catalysts are investigated as a pure selective catalyst for the esterification reaction between acetic acid and butanol to produce butyl acetate and are shown in Table 3 and Table 4. All the prepared samples can be used to cat- alyze the esterification reaction for preparing butyl acetate with different catalytic efficiencies. Samples prepared using higher $\mathrm{pH}$ (basic medium,) show the highest catalytic activity, this mainly due to their large surface area. The phase composition greatly affects the catalytic activity. From literatures, the tetragonal phase of zirconia has highest fraction of surface atoms located on the corners and edges so it shows lowest activation energy and highest surface energy and therefore produces the highest catalytic activity ${ }^{[29,30]}$. Through the data obtained from XRD and BET surface area, as the preparation temperature increases $\left(25-80{ }^{\circ} \mathrm{C}\right)$, the crystallite size of prepared zirconia catalysts decreases and the tetragonal phase percent increases. Increasing the calcinations' temperature of the prepared zirconia catalysts yields samples with large crystallite size and high percent of monoclinic phase, and therefore reducing the catalytic activity. The highest ester yield (60\%) is obtained 
for nanocrystalline zirconia sample prepared in basic medium ( $\mathrm{pH} 9$ ) and at preparation temperature of $80{ }^{\circ} \mathrm{C}$ and calcinations' temperature of $400{ }^{\circ} \mathrm{C}$. This sample (as has been expected) has the highest surface area and higher tetragonal phase percentage (81\%).

\section{Conclusions}

Nanocrystalline zirconia powder with high surface area and high tetragonal phase percentage is prepared by the precipitation method using ammonium hydroxide as a precipitating agent. The crystallite size of the prepared nanocrystalline zirconia decreases with both increasing the preparation temperature and decreasing the calcinations' temperature. Samples calcined at temperature of $800^{\circ} \mathrm{C}$, show high thermal stability. The highest surface area $\left(179.236 \mathrm{~m}^{2} / \mathrm{g}\right)$ is obtained for sample prepared at $\mathrm{pH} 9$ and preparation temperature of $80^{\circ} \mathrm{C}$ and calcined at $400{ }^{\circ} \mathrm{C}$. The corresponding crystallite size and tetragonal phase concentration of this sample is $4.48 \mathrm{~nm}$ and $81 \%$, respectively. The catalytic activity of the prepared nanocrystalline zirconia is not only attributed to surface area but also to the percentage of tetragonal phase. The highest catalytic activities for producing butyl acetate is $60 \%$ and obtained by sample prepared at the basic medium ( $\mathrm{pH} 9$ ) and temperature of $80^{\circ} \mathrm{C}$ and calcined at temperature of $400{ }^{\circ} \mathrm{C}$.

\section{REFERENCES}

[1] W.E. Lee and W.M. Rainforth, Ceramic Microstructures: Property Control by Processing, Chapman \& Hall, London, 1994.

[2] R.E. Juárez, D.G. Lamas, G.E. Lascalea and N.E. Walsöe de Reca, Defect Diffus. Forum 177-178 (1999) 1.

[3] D.G. Lamas, A.M. Rosso, M. Suarez Anzorena, A. Fernández, M.G. Bellino, M.D. Cabezas, N.E. Walso de Recaa and A.F. Craievichc, Scr. Mater. 55 (2006) 553.

[4] J.A. Wang, M.A. Valenzuela, J. Salmones, A. Vázquez, A. Garcia-Ruiz and X. Bokhimi, Catal. To- day 68 (2001) 21.

[5] D.H. Aguilar, L.C. Torres-Gonzalez, L.M. TorresMartinez, T. Lopez and P. Quintana, J. Solid State Chem. 158 (2001) 349.

[6] J.L. Shi and J.H. Gao, J. Mater. Sci. 30 (1995) 793.

[7] A.W.L. Dudeney, Powder Technol. 65 (1991) 207.

[8] A. Clearfield, Rev. Pure Appl. Chem. 14 (1964) 91.

[9] T. Yamaguchi, Catal. Today 20 (1994) 199.

[10] M. Ye and J.G. Eckerdt, J. Catal. 87 (1984) 381.

[11] G.K. Chuah, S. Jaenicke, S.A. Cheong and K.S. Chan, Appl. Catal. A 145 (1996) 267.

[12] J.P. Chang, Y-S. Lin and K. Chu, J. Vac. Sci. Technol. B 19(5) (2001) 1782.

[13] P. Scherrer, Göettinger Nachrichten 2 (1918) 98.

[14] R. Srinivasan and R. de Angelis, J. Mater. Res. 1(4) (1986) 583.

[15] R. Srinivasan, C.R. Hubbard, O.B. Cavin and B.H. Davis, Chem. Mater. 5(1) (1993) 27.

[16] G. Stefanic, S. Music, B. Grzeta, S. Popovic and A. Sekulic, J. Phys. Chem. Solids 59 (1998) 879.

[17] R. Srinivasan, M.B. Harris, S.F. Simpson, R.J. de Angelis and B.H. Davis, J. Mater. Res. 3 (1988) 787.

[18] G.K. Chuah, Catal. Today 49 (1999) 131.

[19] M. Hajir, P. Dolcet and V. Fischer, J. Mater. Chem. 22 (2012) 5622.

[20] T.W. Swaddle, Inorganic Chemistry, Elsevier Inc. 2007.

[21] S. Rajendran, Mater. Forum. 17 (1993) 333.

[22] G.Y. Guo and Y.L. Chen, J. Solid State Chem. 178 (2005) 1675.

[23] H. Adair, P. Denkewicz and S. Ten Huisen, J. Mater. Res. 5 (1990) 2698.

[24] J. Panpranot, N. Taochaiyaphum, B. Jongsomjit and P. Praserthdam, Catal. Commun. 7 (2006) 192.

[25] E. Djurado, P. Bouvier and G. Lucazeau, J. Solid State Chem. 149 (2000) 399.

[26] C. Ray, R. Saha and P. Pramanik, Mater. Lett. 57 (2002) 2140.

[27] C. Ray, K. Pati and P. Pramanik, J. Eur. Ceram. Soc. 20 (2000) 1289.

[28] A. Adamski, P. Jakubus and Z. Sojoka, Nukleonika 51 (2006) 27.

[29] R. Narayanan, C. Tabor, M.A. El-Sayed, Top Catal. 48 (2008) 60.

[30] R. Narayanan and M. El-Sayed, Nano Lett. 4 (2004) 1343. 